\title{
Full speed ahead for CMA's transformation train
}

Previously published at www.cmaj.ca

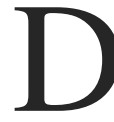
elegates to the Canadian Medical Association annual meeting gave the association the green light to develop its "transformation initiative" and then begin persuading politicians and the general public to adopt a more market-driven health care system.

After ratifying several core controversial resolutions that underpin the initiative, the delegates directed CMA to flesh out the details, get final approval from the board of directors this fall, and launch a campaign to build public and political support.

Outgoing CMA President Dr. Robert Ouellet interpreted the developments as a turning point for Canada's doctors as they've now endorsed a health care system based on "internal market forces" and featuring "more of a role for the private sector."

With $85 \%$ of delegates (192 in favour, 31 opposed and 3 abstentions) supporting a resolution that essentially calls for more competition within the publicly funded health care system and the adoption of activity-based funding of hospitals, Ouellet said it is clear the vast majority of Canadian doctors stand squarely behind transformation.

Yet, debate suggested the medical community is actually more polarized. Many physicians distinguish between "reform" and "transformation" of the system, says Dr. Robert Woollard, vice-chair of Canadian Doctors for Medicare, family physician and professor of family medicine at the University of British Columbia in Vancouver. The initiative remains "vague and fuzzy," while the community isn't entirely enamoured with the CMA's direction and hasn't entirely agreed on the nature of changes that should be made to the health care system.

The CMA should not interpret the vote "as some sort of mandate," Woollard adds, noting that promoters of transformation have not demonstrated that the system is in such disrepair that change must be immediate.

There's a need to first provide "some evidence" that such measures would actually be beneficial, or determine whether they would have a detri- mental impact on equity and access to health care, Woollard says. "The devil is going to be in the details. ... Are we going to move forward thoughtfully or are we going to try everything and see what works? That's not an approach. It's a panic response."

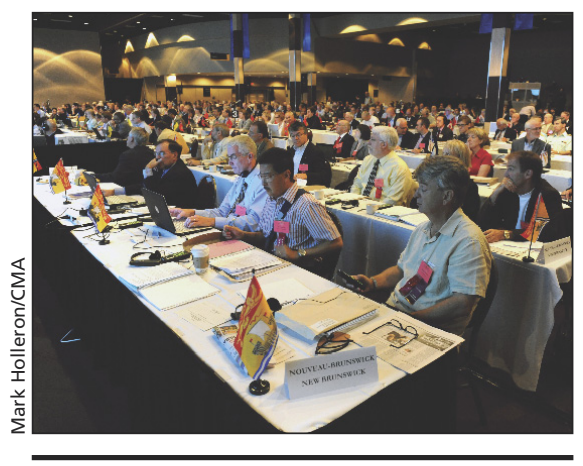

Delegates at the CMA annual meeting in Saskatoon, Saskatchewan, voted to support a resolution that calls for the adoption of activity-based funding of hospitals and more competition within the publicly funded health care system.

Canadian Doctors for Medicare Chair Dr. Danielle Martin fears delegates may have given CMA "carte blanche" to develop the initiative however it likes. "We [doctors] want to see improvement. We want to see innovation. But we don't want the baby thrown out with the bath water. Yet, here we are talking about transformation and none of us will see the document again before our membership dues are used over the next year to implement it."

No one has any real understanding of what the initiative might eventually contain, adds Martin, a family physician in Toronto, Ontario. "In the end, the delegates essentially made a decision virtually unencumbered by any evidence at all."

But Ouellet, who spearheaded the transformation initiative at the Saskatoon, Saskatchewan, gathering, said Canada's doctors are fully aware of what it means to move to a market-driven system and they stand squarely behind that evolution. "It's not a flavour-of-themonth project. The implementation will take some time, but we're committed to doing this. I think there's a will everywhere, maybe not $100 \%$, but [doctors] really want change."
The initiative is predicated on "five goals" for a systemic overhaul of the system: "building a culture of patientcentred care; incentives for enhancing access and improving quality of care [including activity-based hospital funding and pay-for-performance compensation for physicians]; enhancing patient access across the continuum of care [including national pharmacare, longterm and home care programs]; helping providers help patients [electronic record keeping and training more doctors]; and, building accountability/ responsibility at all levels."

Ouellet told delegates that funding models based on services provided have been proven effective in Europe. "The patient becomes a source of revenue rather than an expense. This approach encourages a totally different dynamic because the patient is now a customer to whom the best service possible must be offered."

The delegates were consistently sympathetic to motions underlying the transformation initiative. That include one sponsored by Dr. Eric Wasylenko, an Alberta delegate and chair of CMA's Committee on Health Policy \& Economics that endorsed activity-based hospital funding and other forms of competition would promote efficiencies. "Competition is a fundamental motivator for people," he said, adding that doctors are capable of applying the brakes. "Physicians are well positioned to define the parameters of competition."

Detractors argued that such a regime will encourage an environment in which patients are little more than "commodities." Others noted that Great Britain's introduction of competitive measures led to "fragmentation" within the system, and ultimately pitted, as Ontario delegate Dr. Irfan Dhalla argued, "doctors against doctors and hospitals against hospitals."

Delegates adopted several other transformation-related resolutions, including one calling on the CMA to flesh out "pay for performance and quality measures in family medicine." - Wayne Kondro, CMAJ

DOI: $10.1503 / \mathrm{cmaj} .109-3024$ 